\section{People of New Guinea}

Place and People: an Ecology of $a$ New Guinean Community. By William C. Clarke. Pp. xii +265. (University of California: Berkeley, Los Angeles, and London, November 1971.) $\$ 9$; $\$ 4.30$.

THE author, an American geographer, presents a micro-region study of a "habitat on the edge of human settlement", a remote part of the Bismarck Range of Australian New Guinea. In 1964-5, the time of the study, 154 people occupied the heart of the Ndwimba Basin, making most of their livingexcept for a trickle of traded luxuriesfrom the resources of a few square miles. The first recorded contact, an Australian patrol, occurred only six years before, but when the research began it was already necessary to take steel tools and future road-building projects into account. Evidently the two clans of the Ndwimba Basin will not remain long on the edge.

The book is well titled for a study of an ecosystem ". . . considering human activities and the physical environment as truly interdependent parts of a single system". With much detail of terrain, soils, weather, plant cover, crops, game, and domestic animals Clarke depicts the spatial disposition of Ndwimba people and their activities: gardening, husbandry, hunting, communicating, and collecting materials for food and fabrication. There is a continuous assessment of (1) the inhabitants' views of the habitat in light of (2) the observer's views, and of (3) the decisions and expectations of inhabitants in light of (4) the observable or predictable effects of their decisions : dietary variety and sufficiency, work schedules and yields, the minimization of risk, environmental changes, and the maintenance of community.

The study is rich in immediacy. In each of several detailed instances a specific individual is shown deciding on the location of a specific clearing, with particular crops in view, particular partners or helpers. In one case a specific tree is found growing in the new swidden, the deceased planter recalled, the tree spared for its eventual product. The predilection of individual men for moving about the countryside is noted, the purely aesthetic appeal to them of certain localities, and the ecological implications of their having numerous scattered gardens. To borrow the author's words about the value of studying micro-regions, there emerges ". . . a vivid and accurate image of what is present and what is happening [in one part] of the wider region .... thus lead [ing] to a deeper understanding of the diversity of life and environment in any region and ... the recognition of the important regional consistencies".

The physical domain of a small group of New Guinea gardeners is well realized, full of animals and plants, locations and soils, and of choices and activities for utilizing them. The resident's deep attachment to place is better projected than in most ethnographic monographs devoted to social structure or ritual. Clarke's model is that of a total of varied individual agents rather than a monolithic order that submerges them. Husbandry (or hunting) may seem to some a bit neglected, but one must keep in mind the rich and obtrusive New Guinea plant world, doubtless a more obvious measure of the condition and use of the Ndwimba environment, above all by gardeners.

The aims of the book are modest and sensibly achieved, with no claim to opening up new theoretical vistas. Clarke amply justifies his choices among vistas already open in providing what he himself calls "a qualitative sketch" of a New Guinea people in their place and in evaluating the ecological future of these shifting cultivators whose niche, at present stable and diverse in life forms, may well with impending progress narrow toward uniformity and lessening stability. JAMES B. WATSON

\section{Arctic Ecology}

Animals of the Arctic: The Ecology of the Far North. By Bernard Stonehouse. Pp. 172. (Ward Lock, London, October 1971.) £2.60.

ARCTIC ecosystems are receiving more attention, particularly public attention, than ever before. The daily and weekly press is constantly telling us that the tundra and its flora and fauna, the lakes and forests of the north, and the Arctic seas, are threatened by the oil industry, radioactive fallout, and pesticides, and that the northern ecosystems are especially delicate or "fragile". Perhaps they are, and it is good that the alarms are sounded, but the fragility still has to be demonstrated. Let us hope the demonstration can be made, one way or the other, and in a scientific manner, while there is still time.

Against this background of urgency Dr Stonehouse's book is a timely presentation of the life and the environment of the Arctic for the benefit of the general public, and it is a good example of scientific description and explanation in plain and non-technical terms. The photographs and drawings form a very important part of the book (it is almost a "coffee-table" book), and they are excellent, so good that they could no doubt sell the book by themselves. One would like to know more about the photographers and the artists, beyond the single name alongside each illustration. The text is factual and often a little dry to the palate, but there is no doubt of the wealth of information displayed, or of the sound ecological principles by which it is presented. There are certain high points that strike the reader, such as: "There is an appealing biological economy about Arctic organisms. ... There is none of the ragbag clutter of the tropics, where thousands of species jostle for space and ecology is a tangled net ....". Perhaps a little partisan, but very well said.

The author clearly knows the literature up to the minute, and his book is free from those little mis-statements of fact which infuriate the expert and tempt small minds to point them out with glee, although several controversial issues, such as the famous lemming cycles, the details of the Pleistocene glacial oscillations, and the function of walrus tusks, are perhaps simplified too much, giving the impression that they have been settled once and for all. As a Canadian, I was distressed to see the Canadian Arctic Islands described as lying "north of Canada", which reminds one a little of Sir Leopold McClintock's remark in the first decade of this century that Otto Sverdrup had stopped the northward expansion of the British Empire in North America. But these are small points to quibble about in a work of this high standard. The chapter on the changing polar climate, and the climatic history of the north, is particularly good. The last chapter, on "Man in the Arctic", is good but too short; one would have liked to have this theme developed somewhat, in view of the present anxieties.

I am red-green colour blind, as many men are. I was unable to distinguish between the colours in the Arctic-Subarctic map, and some of the colours in the illustration of the distribution of seals. On consultation with friends of nomal colour vision I found that they had trouble too. Perhaps in the second edition this could be remedied.

This is a handsome, authoritative book, and excellently produced. It should sell well. M. J. Dunbar

\section{Quantitative Sanity}

Lectures on Biostatistics. By D. Colquhoun. Pp. xviii+425. (Clarendon: Oxford; Oxford University: London, November 1971.) $£ 5.50$ boards. $£ 2.75$ paper.

A FEW years ago, many books on applied statistics were inadequate, irrelevant to real problems, or even actively misleading. Standards are now higher; although these major faults have not wholly disappeared a more frequent weakness today is a general dullness. Dr Colquhoun's book is a refreshing exception. He writes as a pharmacologist with long experience in the use of 